\title{
A preliminary study of counterfeit electronic components using Raman spectroscopy
}

\author{
Hana Vašková,, Petr Neumann, and Mikuláš Kozubík \\ Tomas Bata University in Zlin, Faculty of Applied Informatics, Department of Electronic and Measurements, Zlin, Czech Republic
}

\begin{abstract}
In today's world, people are surrounded by diverse electronic devices. Their integral parts are electronic components. In recent years, an increasing incidence of counterfeit electronic components has appeared which may compromise reliability, functionality and other related purposes. The aim of the paper is to determine whether Raman spectroscopy is a suitable method for assessing the authenticity of electronic components on the basis of material analysis. Raman spectroscopy is a powerful method for material identification offering specific information on molecular level. The focus of measurements was on materials of packages and the markings. The polymer-based and ceramic-based electronic components were analysed as well as the paints of the markings. The results of this preliminary study positively indicate the potential to distinguish different materials of electronic components by Raman spectroscopy.
\end{abstract}

\section{Introduction}

The incidence of counterfeit electronic components is an increasingly common phenomenon in our modern world. Counterfeit products can be found at different levels and in different product commodities. In the field of electronics, it is not only fakes of complex products of established companies, but also the number of counterfeits of electronic components themselves that are growing dramatically. These are both, passive components (e.g. capacitors, precision resistors) as well as active components (integrated circuits of various complexity, transistors, etc.) [1].

There are several factors influencing the penetration of counterfeit components into product sets. However, accessibility and price play an important role. There are several types of counterfeit electronic components on the market, to a lesser extent empty cases without any functionality, and sophisticated counterfeits that are hardly recognizable from the original. The largest part, however, consists of the scrap-starter circuits, where they are picked from the discarded electronics and then cleaned or even overwritten. The vast majority of these devices come from uncontrolled waste dumps of electronics in various locations in the world. Counterfeit electronic components are most prevalent in mainland China [2]. Types of counterfeit can be classified into several categories, such as recycled, remarked, defective, cloned, etc. [3]

The danger of counterfeit electronic component lies in the fact that they do not have to meet the technical requirements and reliability guaranteed by the original components. In the case of penetration of counterfeits of electronic components into critical industries such as aviation, aerospace or healthcare, the consequences of failure can be very costly or tragic. In another fields counterfeits negatively impact the innovation, economic growth, employment [4].

The main objectives of this preliminary study is to prove the ability to measure Raman spectra of materials used for packages and markings of electrical components and subsequently, based on the obtained spectroscopic data, verify the possibility for further authentication procedure.

\section{Methods for counterfeit detection}

The detection of counterfeit components is a multilateral issue because of wide range of defects, anomalies and degradation in performance. Therefore, a number of methods can be used for counterfeit detection. The suitability depends on the kind of defect (exterior, interior, physical, electrical, etc.) [4].

The methods used for this purpose, with which we have experience in our department are especially $[5,6]$ :

- Analogue Signature Analysis curve tracing (ASA) - using Counterfeit IC detector. This method uses multichannel counterfeit detectors with several measuring modes and voltage patterns applied sequentially to selected pairs of component outlets. The specific voltamper characteristics of the exemplary component are stored in the instrument memory and the real characteristics of the analyzed components then compared with the stored pattern.

oX-ray diagnostics. The X-ray device is mainly focused on the internal non-destructive analysis of electronic components encapsulated in nonhermetic plastic cases to study the geometry of the chip with respect to the axis of the case. This method also significantly complements to fiber

\footnotetext{
* Corresponding author: vaskova@,fai.utb.cz
} 
laser to allow more accurate focus on the position of the chip in the case prior to laser ablation.

- Fiber laser material of package ablation. This method uses fiber laser enriched with ytterbium atoms. The laser operates in IR region at wavelength $1060 \mathrm{~nm}$ with a maximum output power of $10 \mathrm{~W}$. Laser enables to remove parts of the case material according to diagnostic intention.

- Final wet etching. Method of chemical removal of the relevant part of the plastic case by etching acids.

\subsection{Raman spectroscopy}

Raman spectroscopy is an effective vibrational spectroscopic method with a potential to answer a number of questions related to chemical details on molecular level. This fundamental fact makes this technique suitable for material identification [7]. Method is based on inelastic scattering of incident monochromatic light on the matter. Raman spectroscopy seems to be very promising analytical tool in recent years in number of scientific areas such as chemistry, material science, nanoscience, arts; it is also used for forensic and security purposes [8] and other.

Raman spectroscopy brings many benefits as the method is non-destructive, contactless, highly sensitive, relatively rapid, usable for measuring through transparent glass or polymeric covering layers, applicable to all states of matter and different forms, without special requirements for sample preparation, usable as in situ analysis.

However, inconvenience in measurement can occur when luminescence emerges. Luminescence as a stronger quantum phenomenon can partially mask or even overlap the less intense Raman signal.

Raman spectroscopy has a great potential in nondestructive material analysis. This experience we already have with other type of surveyed materials [9, 10]. Therefore its application on electronic components is being studied to extend the range of methods for deviation detection from original electronic components.

\section{Experiments}

\subsection{Samples}

Eight different samples of electrical components (see Fig. 8), were chosen for the preliminary study of spectroscopic vibrational response of used material. The specifications of the components are listed in Table 1. There are three solo components (no. 1, 2, 3) among the samples and two groups of three (no. 4, 5, 6) and two (no. 7,8 ) samples of the same kind and same producer.

\subsection{Instrumentation}

InVia Basis Raman microscope by Renishaw was performed for measuring all samples. The source of radiation was NIR diode laser with excitation

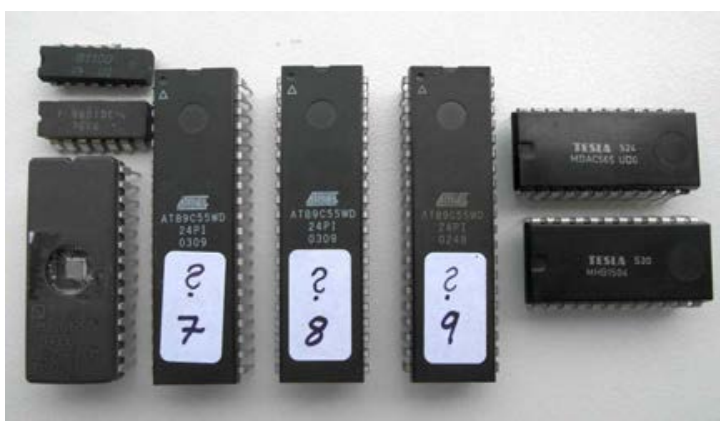

Fig. 1. Samples of electrical components.

Table 1. Formatting sections, subsections and subsubsections.

\begin{tabular}{|c|c|c|}
\hline No. & Assignment & Type \\
\hline 1 & $\begin{array}{l}\text { B110D- } \\
\text { Semicon }\end{array}$ & $\begin{array}{l}\text { Integrated bipolar comparators } \\
\text { with a differential input and } \\
\text { a low impedance output } \\
\text { compatible with all logic forms } \\
\text { for universal application }\end{array}$ \\
\hline 2 & F9601DC & Retriggerable One Shot CDIP14 \\
\hline 3 & $\mathrm{AM} 27 \mathrm{C} 128$ & $\begin{array}{l}\text { Ultraviolet erasable pro- } \\
\text { grammable read-only memory. }\end{array}$ \\
\hline 4 & $\begin{array}{c}\text { ATMEL } \\
\text { AT89C55WD } \\
(7) \\
\text { Batch:0309 }\end{array}$ & $\begin{array}{l}\text { Low-power, high-performance } \\
\text { CMOS 8-bit microcontroller } \\
\text { with } 20 \mathrm{~K} \text { bytes of Flash } \\
\text { prorammable read only memory } \\
\text { and } 256 \text { bytes of RAM. }\end{array}$ \\
\hline 5 & $\begin{array}{c}\text { ATMEL } \\
\text { AT89C55WD } \\
(8) \\
\text { Batch:0309 }\end{array}$ & $\begin{array}{l}\text { Low-power, high-performance } \\
\text { CMOS 8-bit microcontroller } \\
\text { with 20K bytes of Flash } \\
\text { programmable read only } \\
\text { memory and } 256 \text { bytes of } \\
\text { RAM. }\end{array}$ \\
\hline 6 & $\begin{array}{c}\text { ATMEL } \\
\text { AT89C55WD } \\
(9) \\
\text { Batch:0248 }\end{array}$ & $\begin{array}{l}\text { Low-power, high-performance } \\
\text { CMOS 8-bit microcontroller } \\
\text { with 20K bytes of Flash } \\
\text { programmable read only } \\
\text { memory and } 256 \text { bytes of } \\
\text { RAM. } \\
\end{array}$ \\
\hline 7 & $\begin{array}{c}\text { TESLA } \\
\text { MDAC565 }\end{array}$ & $\begin{array}{l}\text { Integrated circuit: monolithic } \\
\text { digital-to-analog converters } \\
\text { with current output }\end{array}$ \\
\hline 8 & $\begin{array}{c}\text { TESLA } \\
\text { MHB1504 }\end{array}$ & Approximation register \\
\hline
\end{tabular}

wavelength $785 \mathrm{~nm}$ with maximum output power 300 mW. A Leica DM 2500 confocal microscope with the resolution $2 \mu \mathrm{m}$ was coupled to the Raman spectrometer. The used total magnifications were 200x and 500x.

\subsection{Measurements}

To reach the best quality spectra, various combinations of measurement parameters were tested. Finally, the spectra were collected with exposure time from 1 to 10 seconds, with 20 or 100 accumulations and with laser power from $1.5 \mathrm{~mW}$ to $300 \mathrm{~mW}$, according to kind of a sample. Raman spectra were acquired in two specific domains: $(100-1300) \mathrm{cm}^{-1}$ and $(800-1900) \mathrm{cm}^{-1}$. All spectra were measured in the dark environment to avoid any interference. 


\section{Results and discussion}

For the material identification based on Raman spectra, the layout of the bands according to x-axis (Raman shift) is crucial. This layout is connected to specific vibration of chemical bonding in the structure of material, caused by the incident laser radiation. The intensity of single bands inform about quantity of vibrating bonds of the same chemical composition, i.e. how much of the specific bonding (C-C, C-H, etc.) is in the material.

Each chemical compound or its modification has a unique Raman spectrum. This feature brings the benefit of recognition different materials. If the counterfeit package is fabricated from different material compared to original, it is recognizable from Raman spectra. The materials of the samples are usually known only partly from the datasheet, if this information is available at all.

\subsection{Packages}

The colours of all the packages are dark grey to black, what is rather a disadvantage for Raman spectroscopic measurement due to high absorption of radiation by a sample. Hence, spectra with higher noise are obtained.

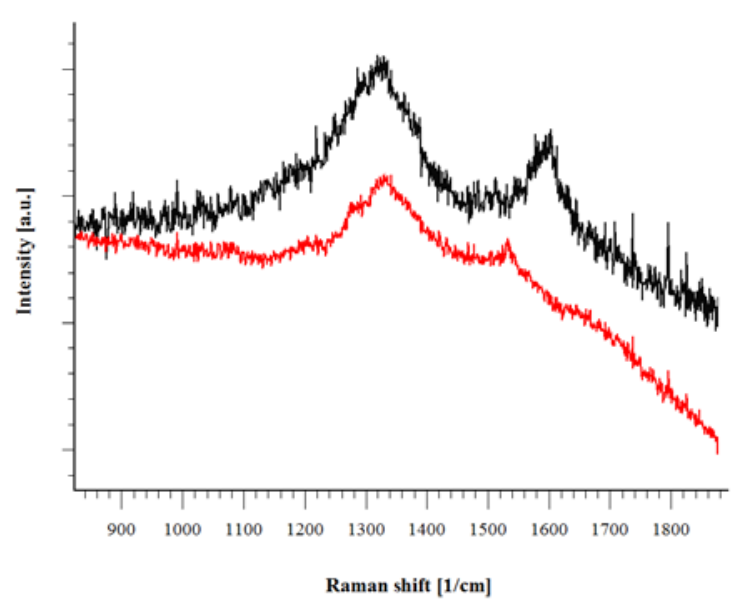

Fig. 2. Samples of electrical components, sample no. 1 (upper), sample 2 (lower).

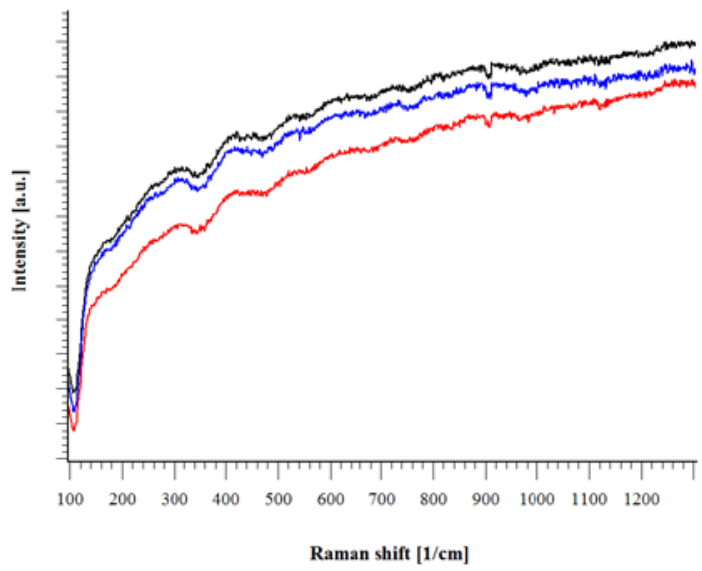

Fig. 3. Raman spectra of packages of samples no. 4, 5, 6. (from the top).
However, some of specific bands are recognizable in Raman spectra. Materials of packages are polymer-based (no. 1, 4-8) and ceramic-based (no. 2, 3). The difference in material response of polymer package of sample 1 and ceramic package of sample 2 is demonstrated in Fig. 2.

The measurement repeatibility was successfully tested on all samples. Raman spectra of samples no. 4, 5, 6 from the same producer ATMEL are displayed in Fig. 3. Spectra from all three samples show compliance.

\subsection{Markings}

There are two main types of markings on the packages of the surveyed samples. Markings are burned by laser or the die is applied on the surface of the case. Laser markings usually show higher noise and worse signal in comparison to Raman spectrum of the package material as can be seen from spectra of sample no. 7 presented in Fig. 4. An optical microscopy with high magnification serves for the visual survey of the irregularities on the surface. A detail of the paint marking on the sample no. 7 is depicted in Fig. 5. Using the database of Raman spectra, the results show a significant content of $\mathrm{TiO}_{2}$, as shown in Fig. 6.

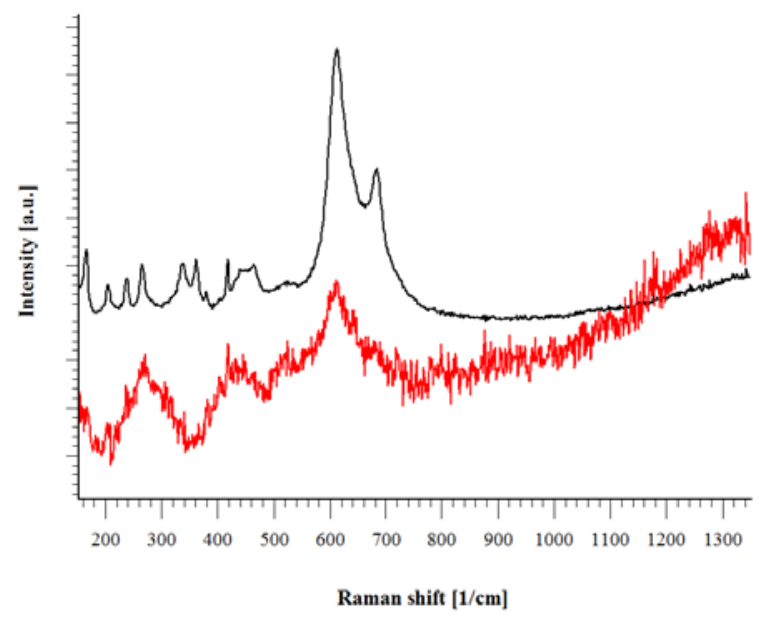

Fig. 4. Raman spectra: of package material (upper), focused on burned markings (lower), sample no. 2 .

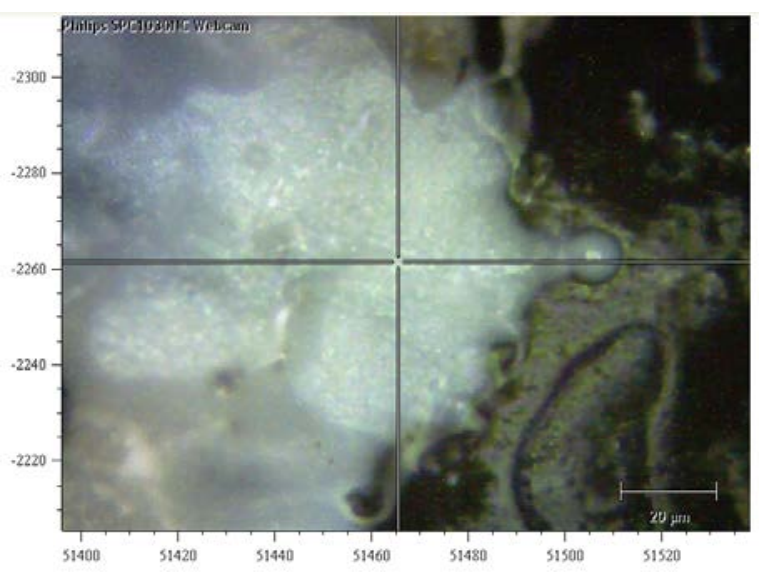

Fig. 5. Microscopic detail of the paint markings, sample no.7. 


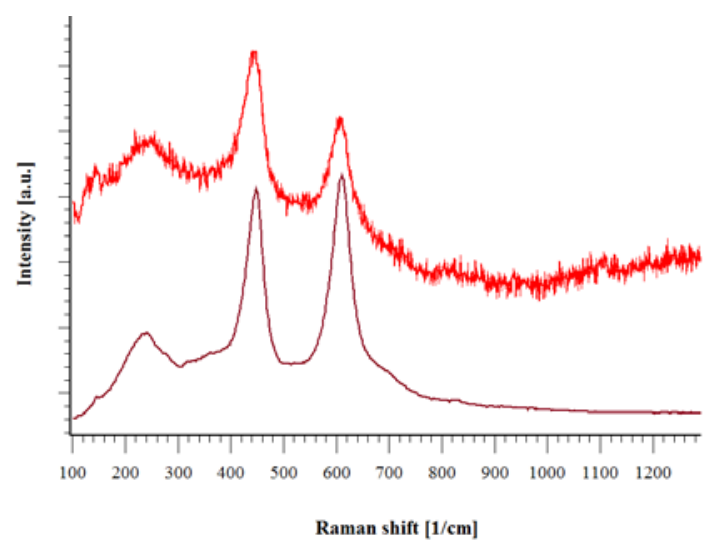

Fig. 6. Comparison of measured Raman spectra of marking material, samples no. 7(upper) and pure rutile $\left(\mathrm{TiO}_{2}\right)$ from the spectral database (lower).

\subsection{Chips}

Using optical microscope coupled to Raman spectrometer, the target area can be up to the order of micrometers. The detail of chip of sample no. 3 is in Fig. 7. Raman spectra confirm the content of pure silicon on chips (Fig. 8) - which is essential for their functionality.

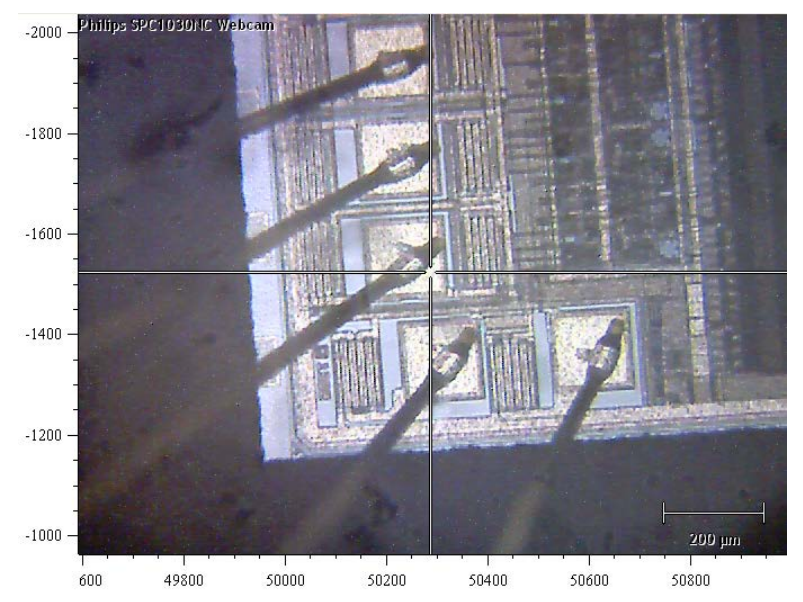

Fig. 7. Microscopic detail of the chip, sample no.3.

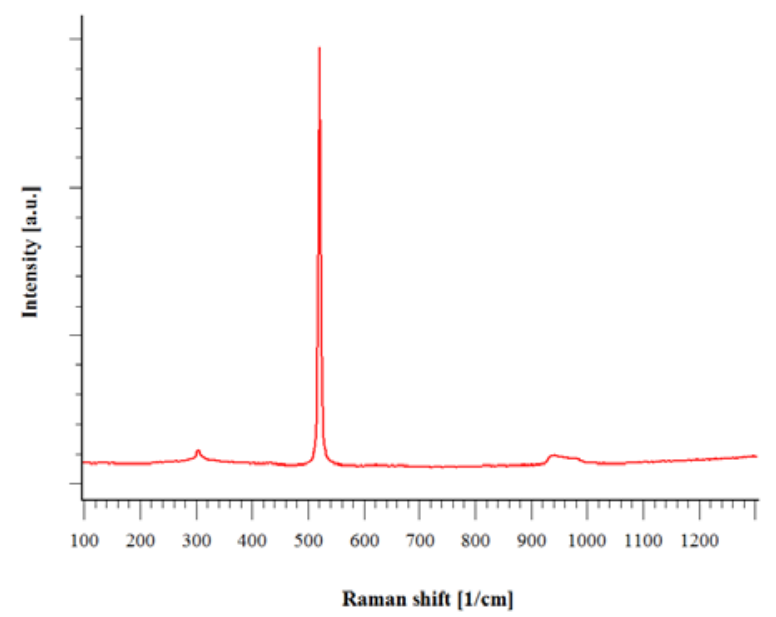

Fig. 8. Raman spectrum of the chip material.

\subsection{Further steps}

There are two main aims for the further work. Firstly, measurement of larger number of components from reliable suppliers and verified by other methods. Secondly, to create a database based on the obtained spectral data for comparing with the questioned components. A thorough analysis and comparison of materials and their spectra acquired from different components is also expected.

\section{Conclusions}

Currently, counterfeit electronic components can be revealed according to a number of characteristics external, internal, functional, electrical, visual, etc. Raman spectroscopy was used as an innovative method for this purpose. The carried out preliminary study showed the potential of Raman spectroscopy for assessment of materials used on the electronic components. The main interest was focused on material of packages and the paint used for markings. Even if the Raman scattering from the packages is in many cases rather weak, Raman spectral data offer valuable information about the materials. A prerequisite for a common use of Raman spectroscopy is creation of the spectral database of guaranteed electronic components. Raman spectroscopy has the potential to extend the range of non-destructive, fast and reliable methods for counterfeit electronic component detection.

This work was supported by the Ministry of Education, Youth and Sports of the Czech Republic within the National Sustainability Programme project No. LO1303 (MSMT7778/2014) and also by the European Regional Development Fund under the project CEBIA-Tech No. CZ.1.05/2.1.00/03.0089.

\section{References}

1. P. Neumann, Odborný časopis pro vývoj a výrobu v oboru elektroniky (2011)

2. M.M. Tehranipoor, U. Guin \& D. Forte, Counterfeit Integrated Circuits (Springer, Cham., 2015)

3. U. Guin, D. DiMase, M. Tehranipoor, J Electron Test (2014)

4. H.W. Hewett, In SMTA Int. Conf. (2010)

5. P. Neumann, J. Houser, M. Pospíšilík, P. Skočík, \& M. Adámek, Proc. of DAAAM (2015)

6. P. Neumann, Odborný časopis pro vývoj a výrobu v oboru elektroniky (2015)

7. J.M. Chalmers, G.E. Howell, M.D. Hargreaves. Infrared and Raman spectroscopy in forensic science (Wiley, 2012)

8. G.S. Bumbrah, R.M. Sharma, Egypt J Forensic Sci 6, 3 (2016)

9. H. Vaskova, MATEC Web Conf (2016)

10. H. Vaskova, M. Buckova, MATEC Web Conf (2017) 